\title{
Aplicação de dinâmicas educativas sobre saúde durante a Semana de Saúde Escolar: relato de experiência
}

\author{
Luíza Trindade Vilela*; Patrícia de Andrade Risso**; Thays Alves Barbosa***; Maria Elisa Barbosa

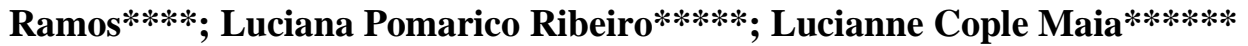

* Mestranda, Departamento de Odontopediatria e Ortodontia, Faculdade de Odontologia. UFRJ

** Professora Associada, Departamento de Clínica Odontológica, Faculdade de Odontologia da UFRJ

*** Terapeuta Ocupacional graduada pela UFRJ

**** Professora Associada, Departamento de Estomatologia, Faculdade de Odontologia da UFRJ

***** Professora Adjunta, Departamento de Odontopediatria e Ortodontia, Faculdade de Odontologia da UFRJ

****** Professora Titular, Departamento de Odontopediatria e Ortodontia, Faculdade de Odontologia da UFRJ

Recebido: 29/03/2020. Aprovado: 30/11/2020.

\begin{abstract}
RESUMO
A extensão universitária permite que a universidade se aproxime da sociedade e que a troca de saberes possa permear a construção do conhecimento técnico-científico. O objetivo deste artigo é descrever a experiência do desenvolvimento de ações de promoção de saúde geral e bucal, desenvolvidas em um projeto de extensão da Faculdade de Odontologia da Universidade Federal do Rio de Janeiro. Desta forma, atividades lúdicas foram selecionadas como meios didáticos e aplicados em escolares (08 a 13 anos) da Escola Municipal Henfil, CIEP HENFIL - RJ. Os temas em saúde foram selecionados de acordo com a realidade dos escolares e envolveram os órgãos dos sentidos criando a Dinâmica dos sentidos e a Dinâmica do Autocuidado. A equipe executora foi formada por docentes, técnicos administrativos e discentes de graduação. Participaram ativamente das ações 150 crianças que demonstraram interesse e curiosidade. Ademais, os escolares criaram vínculos com os discentes de graduação, relações de cumplicidade, se sentindo seguros para compartilhar seus anseios e inseguranças quanto aos assuntos abordados. O presente trabalho destaca o processo de construção da ideia, delineamento das atividades, aquisição do material, capacitação para execução e aborda a aplicação das dinâmicas, as experiências e principais resultados.
\end{abstract}

Descritores: Relações Comunidade-Instituição. Ensino. Saúde. 


\section{INTRODUÇÃO}

O processo de extensão universitária se constitui em um conjunto de ações, fomentadas pela articulação do ensino e da pesquisa na tentativa de viabilizar a relação de transformação entre universidade e comunidade. Tal processo tem como características a educação, cultura, ciência e a capacidade de promover a troca de saberes entre o meio acadêmico e o meio popular, devidamente estruturados, fruto da concepção do conhecimento proveniente do confronto entre a teoria e a realidade prática, democratizando o conhecimento acadêmico e permitindo a participação efetiva da comunidade no meio universitário ${ }^{1}$. A extensão universitária, sob a razão da indissociabilidade entre ensino, pesquisa e extensão, é um sistema interdisciplinar educativo, cultural, científico e político que impulsiona a interação transformadora entre universidade e demais setores da sociedade ${ }^{2}$.

Dentre as diretrizes que orientam a formulação e implementação de suas ações, os projetos de extensão detém o impacto na formação do estudante e na transformação social, significando respectivamente, que atividades extensionistas constituem aportes decisivos à formação do estudante, ampliando seu universo de referência e promovendo o contato direto com as grandes questões do mundo contemporâneo. Além disso, impactam na transformação social através da inter-relação da Universidade com demais setores da sociedade, com vistas a uma atuação transformadora, voltada para os interesses e necessidades de grande parte da população ${ }^{3}$.

Em acréscimo, a extensão deve promover a inclusão social, diminuindo a distância entre a universidade das comunidades adjacentes, de forma a sustentar o vínculo entre ensino, pesquisa e extensão $0^{2,3}$. Considerando a significância que a extensão vincula à formação dos estudantes, a eficácia da vinculação da Universidade com a sociedade e seu entorno socioeconômico, as diretrizes curriculares nacionais para os cursos da saúde ${ }^{4,5}$, a regulamentação da extensão como atividade acadêmica obrigatória dos cursos de graduação no Brasil, na forma de componente curricular $^{6}$, a Universidade Federal do Rio de Janeiro (UFRJ), regulamentou o registro e inclusão das atividades de extensão nos currículos dos seus cursos de graduação, com a obrigatoriedade de que no mínimo dez por cento da carga horária total exigida seja para a atuação dos alunos em atividades extensionistas ${ }^{7,8}$.

Neste sentido, diferentes projetos de extensão foram desenvolvidos na Faculdade de Odontologia da UFRJ (FO-UFRJ), entre os quais destaca-se o projeto de extensão: "Saúde na escola: educação, prevenção e diagnóstico de problemas da cavidade bucal, audição e fala de pré-escolares e professores", que possuía uma equipe multidisciplinar de diferentes especialidades da saúde, com a participação de docentes, técnicosadministrativos, discentes de pós-graduação e graduação e obteve apoio financeiro do Ministério da Educação, por meio do edital PROEXT/MEC/SESu (2014/2015) de fomento à extensão universitária. $\mathrm{O}$ projeto visou à produção e difusão de novos conhecimentos e metodologias na área de educação, ensino, prevenção e diagnóstico das principais doenças bucais, da audição e da fala, tendo como público-alvo, préescolares, escolares, e professores de escolas municipais do Rio de Janeiro. As ações eram interdisciplinares, interinstitucionais e interprofissionais, tendo como principal eixo levar a informação e trabalhá-la junto ao público-alvo, na busca de um processo que facilitasse a incorporação dos saberes e fomentasse a apropriação do conhecimento por parte desses atores no sentido de reformulação de atitudes em relação à saúde bucal, auditiva e de fala, especialmente desenvolvendo o autocuidado.

Este projeto baseou-se na atuação na escola, 
pois é um ambiente propicio às práticas educativas em saúde, tendo um papel fundamental na aquisição de estilos de vida saudáveis e na prevenção de comportamentos nocivos, pois a proximidade com a comunidade permite que se desenvolvam ações prioritárias, apontadas pelos próprios indivíduos em seus ambientes, visando o compromisso social com as suas comunidades ${ }^{9}$, promovendo assim a educação em saúde, que poderá possibilitar ao escolar a mudança de hábitos de saúde, apoiando-os na conquista de autonomia, e formulando ações que objetivam a apropriação do conhecimento sobre o processo saúde-doença ${ }^{10}$.

Neste contexto, o presente artigo objetivou relatar as experiências vividas na aplicação de dinâmicas educativas sobre saúde em um ambiente escolar. Assim, relatam-se a idealização, o delineamento, a confecção, a testagem e a aplicação de dois meios didáticos, ou seja, de duas dinâmicas para educação em saúde no ambiente escolar, visto que a escola é um ambiente privilegiado para que o conceito de saúde seja trabalhado junto a crianças e adolescentes, em razão destes passarem ali grande parte do seu dia e nela construírem uma parcela significativa de sua identidade $^{11}$.

\section{RELATO DE EXPERIÊNCIA Proposta Geral}

O presente estudo apresenta um relato de experiência que surgiu da atividade intitulada: "Aplicação de dinâmicas educativas sobre saúde durante a semana de saúde escolar", desenvolvida na semana de saúde escolar, realizada no período de 18 a 22 de maio de 2015, vinculada ao projeto de extensão "Saúde na escola: educação, prevenção e diagnóstico de problemas da cavidade bucal, audição e fala de pré-escolares e professores", que obteve apoio financeiro do edital PROEXT/MEC/SESu (2014/2015) e com o apoio logístico e de pessoal da Secretária Municipal de
Saúde do Rio de Janeiro (SMS-RJ).

\section{Local de desenvolvimento da proposta}

A atividade foi realizada nas dependências da Escola Municipal CIEP Henfil (CIEP HENFIL - RJ), localizada no bairro do Caju, na cidade do Rio de Janeiro. O público alvo foram os escolares ( 8 a 13 anos de idade) de diferentes séries escolares. O Caju é um bairro que possui baixo índice social, estando entre os menores do município do Rio de Janeiro ${ }^{12}$.

\section{Delineamento Metodológico}

As atividades foram desenvolvidas considerando a faixa etária (8 a 13 anos de idade), a condição socioeconômica e a realidade da escola pública, na qual o público-alvo estava inserido. A metodologia de planejamento das ações e respectivas atividades relacionadas foi feita da seguinte forma: (1) idealização e definição do tema; (2) reuniões semanais entre a equipe executora para revisão de literatura e discussão das ideias relacionadas ao tema e delineamento da metodologia a ser empregada; (3) confecção do material didático; (4) testagem da atividade através do projeto piloto; (5) aplicação dos meios didáticos. Nas reuniões semanais participaram os discentes de graduação vinculados ao projeto, principalmente os bolsistas PROEXT/MEC (2015), supervisionados por docentes ou técnicos administrativos (dentistas, fonoaudiólogos, ou terapeutas ocupacionais) da UFRJ.

A metodologia escolhida foi o uso de atividades lúdicas, opção ideal a ser trabalhada durante a Semana de Saúde do Escolar, em razão de que com a prática de jogos e brincadeiras, as crianças expandem seus conhecimentos, desenvolvem as linguagens, exploram e manipulam objetos, organizam seus pensamentos, descobrem e respeitam regras, e se socializam com as demais crianças ${ }^{13}$. As atividades lúdicas de 
eleição foram as dinâmicas educativas com o objetivo de despertar o interesse e atrair atenção dos escolares para as atividades com a transmissão do conhecimento de maneira interativa. Novas estratégias pedagógicas na promoção do ensino e aprendizagem apresentam-se em ascensão, é o caso das metodologias ativas, como as atividades lúdicas, ações de eleição nesse trabalho, que constituem instrumentos eficazes no processo de ensino e aprendizagem ${ }^{14}$.

Devido à diversidade de agentes que podem influenciar na saúde bucal, assim como na saúde da audição e da voz, objetivamos abordar temas do cotidiano relacionados à saúde, tais como higiene corporal e bucal, cárie dentária, halitose, uso de piercings, protetores bucais, traumatismo dentário, tabagismo, clareamento dental, bruxismo, uso de fones de ouvido e frequentar ambientes ruidosos. Todos os aspectos foram abordados tendo como pano de fundo os sentidos humanos e o autocuidado. $\mathrm{O}$ desenvolvimento de estratégias educativas lúdicas, abordando temas bastante comuns e acessíveis aos escolares, por meio de dinâmicas foi aprovado pelo grupo, e as dinâmicas de escolha foram "dinâmica dos sentidos" e "dinâmica do autocuidado" por fazerem parte do universo cotidiano dos escolares, a fim de que o público-alvo se identificasse com os assuntos e questões abordadas.

\section{1) Dinâmica dos sentidos}

A seleção dos temas foi por meio de diálogos com escolares de idade similar ao público-alvo. Temas do interesse do público-alvo eram imprescindíveis para que os escolares se sentissem estimulados e pré-dispostos a participar. Nesta dinâmica foram trabalhadas as diversidades de agentes que podem influenciar na saúde bucal, assim como na saúde da audição e da voz. Os assuntos selecionados foram associados aos cinco sentidos humanos (visão, tato, olfato, audição e paladar) para que através de uma aproximação gradativa dos sentidos, os assuntos fossem explorados e se tornassem mais dinâmicos e interativos. Para tanto, levou-se em consideração o fato de que no decorrer do processo ensino aprendizagem atividades estimulando o desenvolvimento das habilidades sensoriais, como as dinâmicas realizadas, devem ser propostas com maior frequência, visto que os sentidos são explorados em diversos contextos das relações sociais humanas ${ }^{15}$.

Tato: foram selecionadas modelos de arcadas dentárias sadias e doentes, esses modelos eram reproduções em gesso de arcadas dentárias em tamanho real, e também macromodelos, em dimensões aumentadas, com o objetivo de explorar o sentido do tato por parte dos escolares, que foram estimulados a realizar a palpação dos modelos, descrevendo o que sentiam, e se acreditavam estar percebendo padrões dentários normais, ou fora da normalidade. E então os discentes em Odontologia os explicavam e ensinavam o que poderiam causar aquelas alterações, e como fazer a prevenção ou as tratar.

Visão: foi feita a seleção de fotografias na literatura e no banco de imagens da disciplina de Odontopediatria da FO-UFRJ. Optamos pela escolha de fotos de casos normais e que diferissem da normalidade, que fossem impactantes perante o olhar dos escolares. E durante a dinâmica foi explicado o que estava retratado nas fotos, e como ocorria a prevenção ou o tratamento.

Olfato: foi trabalhada a assimilação de odores representativos da halitose. Selecionamos itens com odores agradáveis e desagradáveis, para apresentar aos escolares o bom hálito e mau hálito, aproveitando para que os discentes de graduação os orientassem sobre o assunto, e ensinassem formas de prevenção e tratamento.

Paladar: a experimentação de diferentes sabores foi a forma de eleição para essa abordagem. Ademais, foi explorada a anatomia da língua para 
melhores explicações dos distintos gostos sentidos pelo corpo humano, para que os escolares tivessem um conhecimento ampliado de seus próprios corpos.

Audição: foi trabalhada através de sons representativos de alterações da condição de normalidade. E também ampliada com explicações e modelos da anatomia do ouvido.

Após a idealização da proposta, delineamento das atividades e confecção do material, estes foram apresentados ao grupo de trabalho, durante as reuniões semanais e aprovado após ajuste. Para a verificação da atividade foram realizados testes pilotos, em uma escala de menor abrangência, servindo de orientação para realização da atividade propriamente dita; estes testes foram executados internamente na FOUFRJ, nos quais foi realizada a aplicação prática da dinâmica dos sentidos para grupos de pacientes do Departamento de Odontopediatria e Ortodontia, de mesma faixa etária que o público alvo do projeto. Nesta proposta inicial, cada material foi apresentado, às crianças e adolescentes sendo feita a aproximação gradativa daqueles com os cinco sentidos humanos. Explicações foram atribuídas a cada objeto da dinâmica, testando sua eficácia, e permitindo o aprimoramento da mesma, pois através deste teste foi possível obter uma resposta por parte dos participantes a respeito da dinâmica, tornando possível a análise do que estava funcionando como o esperado, e o que não seguia a expectativa. E esta resposta foi positiva, visto que $\mathrm{o}$ teste foi bem recebido pelas crianças e adolescentes, que se mostraram interessados em participar, e receptivos em aprender coisas novas, além de aproximarem o conteúdo com situações vividas por eles, e por pessoas próximas.

As principais modificações realizadas após o teste piloto, foram em relação a aparência e cor dos materiais, pois foi notório maior interesse pelos objetos mais bonitos e coloridos. Os participantes foram atraídos principalmente pela questão visual, pois vinham até as dinâmicas estimulados principalmente pela busca do entendimento do que as fotos em exposição representavam, ou o que significavam os modelos de arcadas dentária com aspectos distintos, confeccionadas em gesso. Apenas após a realização dos testes pilotos, e realização das modificações necessárias, visando o aprimoramento dos objetos da dinâmica, a ação foi realizada no ambiente escolar (figura 1). Devido à variação de idade do público-alvo adaptações durante as apresentações foram necessárias, como adequação de linguagem, e a quantidade de conteúdos transmitidos, garantindo assim uma maior e melhor participação e assimilação por parte de todos.

\section{2) Dinâmica do Autocuidado}

Ainda envolvendo os sentidos humanos, foi realizada a dinâmica do autocuidado (figura 2), criada para atender à demanda da direção do CIEP HENFIL - RJ que solicitou a execução de atividades sobre higiene pessoal, e cujo objetivo foi conscientizar os escolares sobre a importância da execução dos cuidados pessoais, de forma lúdica e sensitiva, orientando-os sobre sua própria higiene, e apresentando de forma aprofundada costumes, hábitos e experiências dos próprios escolares, podendo sugerir atitudes mais corretas, condutas mais apropriadas e saudáveis. O material selecionado para compor a dinâmica foram itens de higiene pessoal, como shampoo, sabonete, desodorante, escova de dente, pasta de dente, esponja de banho, cortador de unhas, cotonetes e papel higiênico, que foram colocados em uma caixa, intitulada caixa da higiene. Após a seleção estes itens foram apresentados durante as oficinas de produção de conteúdos e materiais para as dinâmicas. Após aprovado, foi levado ao ambiente escolar, no qual a dinâmica do autocuidado foi executada durante dois dias. Para realizar a atividade foram utilizados além dos itens de higiene 


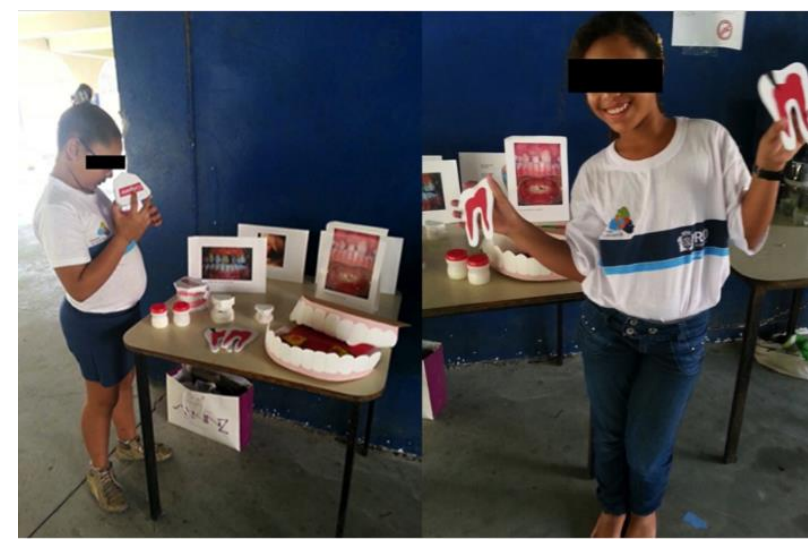

Figura 1. Participação dos escolares na dinâmica dos sentidos

pessoal, fichas que retratavam atividades relacionadas à higiene pessoal, com desenhos coloridos e chamativos feitos por universitários bolsistas PROEXT/MEC/SESu da Escola de Belas Artes da UFRJ, para despertar ainda mais a vontade de participar dos escolares. A atividade foi realizada individualmente por cada escolar, que era instruído a escolher uma ficha desenhada (desenhos que abordavam os cuidados necessários com a saúde geral e higiene pessoal). Posteriormente, foram desafiados a buscar dentro da caixa da higiene, os produtos de cuidados pessoais correspondentes com a prática da ficha desenhada, e sem o auxilio do sentido da visão. Os escolares eram vendados, sendo estimulados a procurar por outros sentidos que não a visão, o que tornava a atividade mais interativa e divertida, despertando o interesse dos escolares e motivandoos. Ao fim da atividade, com a ficha desenhada e o item de higiene em mãos, os escolares eram instruídos pelos discentes de graduação, que transmitiam conhecimentos a respeito do assunto, com ênfase ao modo de manuseio, e a importância do uso daquele item.

\section{Resultados das atividades e Discussão}

O público-alvo demonstrou uma reação

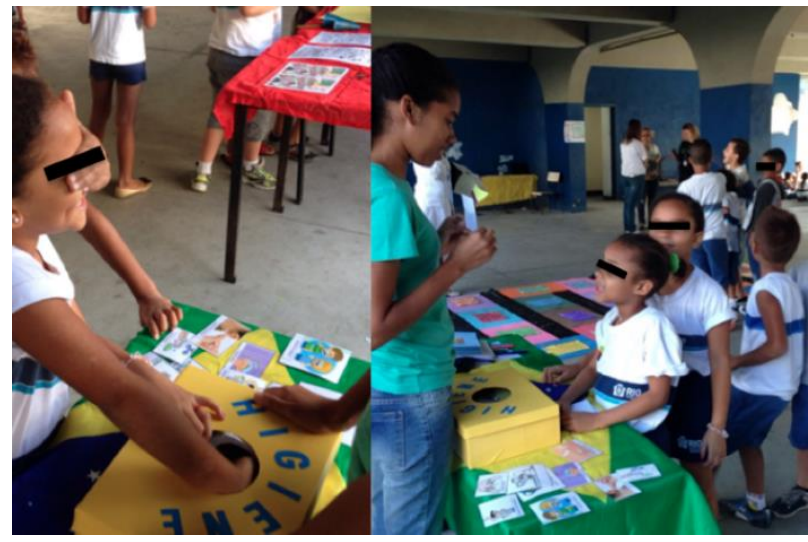

Figura 2. Aplicação da dinâmica do autocuidado

muito positiva em relação a dinâmicas, visto que se interessavam muito pelos temas por estarem envolvidos com assuntos que vivenciam diariamente, e se mostraram pré-dispostos a interagir com os extensionistas durante as atividades. Foi nítido o interesse pelas dinâmicas. Como previsto, aguçar a curiosidade dos escolares é uma forma de envolve-los no projeto, e atraí-los a querer participar. É notório que situações as quais aproximam os escolares da prática, resultam em expressiva contribuição para um maior aprendizado, além do desenvolvimento de competências e habilidades relacionadas ao assunto $^{16}$.

Foi observado que durante toda a execução das atividades, os escolares aproximavam o conteúdo das situações retratadas de seus cotidianos, ou ao cotidiano de pessoas próximas a eles, relembrando situações vividas pelos mesmos, ou por pessoas próximas, como relatos de trauma, fraturas, cáries, má higiene, uso abusivo de fone de ouvidos, problemas relacionados aos piercings, entre outros, atingindo um dos objetivos do projeto, a aproximação gradativa dos conteúdos a situações do cotidiano dos escolares.

Outra observação importante foi que, mediante o interesse e participação dos escolares 
pelas dinâmicas, o conhecimento pôde ser transmitido por meio de uma interação dinâmica, concretizando o objetivo de que os escolares se sintam mais orientados sobre os respectivos temas, descobrindo e redescobrindo a origem de possíveis problemas, e estando aptos para futuramente tomar decisões mais seguras, a fim de prevenirem problemas que possam vir a afetar a sua saúde bucal e auditiva, e também uma substituição de hábitos, por práticas mais saudáveis, tanto para si, quanto para seus familiares. Práticas envolvendo os cinco sentidos, além de se tratar de uma novidade no processo ensino-aprendizagem, podem contribuir para desenvolvimento e aprimoramento de habilidades de percepção, cuidados e relação interpessoal, como ocorreu também no estudo de Franco (2017, p.193) cujos sentidos foram eleitos para serem trabalhados em atividades lúdicas envolvendo saúde ${ }^{15}$.

As temáticas abordadas no projeto resultaram da demanda da escola e seus alunos, verificada através das dúvidas dos mesmos, de modo que esses participem e consigam identificar as situações retratadas nas atividades em seus cotidianos, suas realidades, e sintam-se mais orientados e seguros quanto a sua saúde oral.

Um dos fatores mais significativos para a promoção da saúde é a educação. E o ambiente escolar pode ser favorável a formação de cidadãos capazes de atuar em prol de melhorias nos níveis de saúde pessoal e da coletividade ${ }^{17}$. Espaço onde se constituem os cidadãos é a escola; nela surge uma maior possibilidade de promover ações educativas que levem à reflexão sobre o que é ter uma vida saudável ${ }^{18 .}$

A Organização Mundial de Saúde (OMS), no documento "Promoción de la Salud mediante las Escuelas" reconhece a relação que existe entre educação e saúde; e entende que o conhecimento pode ser empregado para que atividades que melhorem a educação e aumentem o potencial de aprendizagem e ao mesmo tempo que levem a melhora da saúde, sejam estabelecidas nas escolas, em razão de que a boa saúde apoia um aprendizado proveitoso e vice-versa ${ }^{19}$. Apoiando-se nessa relação saúde e escola, foram criadas ações para aplicação de atividades lúdicas no ambiente escolar. A aplicação de recursos lúdicos favorece a aquisição de informações de modo simples e incisivo, contribuindo para o ensino, pois atraem o interesse dos escolares colaborando para uma mudança de hábitos, de comportamentos, como também em subsídios para os profissionais da saúde no atendimento infantil, além do mais, podem permitir que a criança revele o que sente e pensa, por meio das brincadeira ${ }^{20,21,22}$, fato observado no presente trabalho.

As ações de extensão permitem aos discentes da graduação serem inseridos na vida dos escolares, passando a conhecer costumes, cotidiano e as principais dúvidas dos mesmos, conhecendo um pouco mais a fundo uma realidade diferente da conhecida pelos discentes de graduação. Agregando conhecimentos e valores não apenas para a vida profissional, mas também contribuindo para a vida pessoal dos discentes de graduação envolvidos. Foi notória a troca de experiências baseadas nas histórias individuais, na qual os escolares aproximavam o conteúdo trabalhado com situações cotidianas, e dividiam as mesmas com os graduandos envolvidos, com os quais os escolares criaram vínculos, relações de cumplicidade, se sentindo seguros para compartilhar seus anseios e inseguranças quanto a determinados assuntos. Relação de cumplicidade esta, que motivou ainda mais os discentes da graduação a se envolverem com o projeto, e proporcionarem o melhor de si durante a execução das dinâmicas. Além de capacitação e treinamento destes no âmbito do ensino.

Foi plena a interação dos escolares com as atividades. Eles se mostraram estimulados e pré- 
dispostos a participar das ações. A reação positiva dos escolares em relação às dinâmicas foi comprovada, em razão de que os mesmos demonstraram vontade de repetir as atividades e solicitaram a presença dos discentes de graduação no ambiente escolar com maior frequência. Ademais ainda era possível constatar a assimilação de conteúdos por partes dos escolares, ao observálos ensinando e explicando os assuntos trabalhados nas dinâmicas, uns para os outros. Como previsto, contatou-se que aguçar a curiosidade dos escolares é uma forma de envolvê-los, atraí-los a participar e torna a assimilação do conteúdo algo natural, influenciando no poder de transformação das realidades. Demais relatos de experiência confirmam que despertar a atenção dos escolares é uma forma eficaz de ensino, contribuindo para a busca por novos conhecimentos e consequentemente ampliando saberes ${ }^{23,24}$.

O desenvolvimento de estratégias educativas lúdicas, abordando temas bastante comuns e acessíveis aos escolares, em formato simples e envolvente, como a dinâmica dos sentidos e do autocuidado, no âmbito da extensão universitária mostra a importância do papel dos discentes de graduação na promoção da saúde nas escolas ${ }^{25}$. Uma vez que estes podem atuar estimulando a busca de conhecimento pelos escolares, de um modo criativo, que aproxime o escolar, o faça querer participar, interagir, e não apenas receber o conhecimento. Estimula os escolares a pensarem, a fazer uma reflexão sobre seus atos, sobre suas incertezas, e dúvidas sobre saúde. Ademais contatou-se que aguçar a curiosidade dos escolares é uma forma de envolvê-los, atraí-los a participar e torna a assimilação do conteúdo algo natural. Com elas é possível fazer com que os escolares se recordem do que aprenderam e vivenciaram, e sintam-se então mais seguros sobre maneiras de como promover sua saúde, evitando hábitos que não a favoreçam, e os substituindo por hábitos saudáveis. Deste modo, se tornam aptos para tomar decisões seguras, visando à prevenção de problemas que possam vir a afetá-los, além de orientar pessoas de seu convívio.

Em relação à direção da escola, mostrou-se muito satisfeita com a execução do projeto, principalmente por terem sido abordados assuntos que eram demanda da própria escola. Como resultado obtido tem-se a conscientização dos alunos sobre a importância da execução dos cuidados pessoais, trabalhada de forma lúdica e sensitiva, orientando-os sobre sua própria higiene e feitas sugestões sobre condutas apropriadas e saudáveis. Além disso, houve grande conscientização da diversidade de agentes que podem influenciar na saúde bucal, assim como na saúde da audição e da voz, através da dinâmica dos sentidos. Dessa forma, acreditamos que o objetivo de contribuir para melhoria da qualidade de vida dos escolares, e da capacitação dos discentes de graduação extensionistas foi atingido.

A respeito das vulnerabilidades da execução do projeto, podemos citar que o referido projeto de extensão em execução no ambiente escolar não foi previamente apresentado e esclarecido a todos os docentes, coordenadores e funcionários da escola, para que estes pudessem ter ampliado sua participação, opinando e contribuindo com os métodos e propostas de planejamento, colaborando e contribuindo positivamente, já que conhecem melhor o cenário e o público-alvo das atividades. Professores têm intenso convívio com os escolares, logo é fundamental a parceria entre eles e os programas de educação, de forma a contribuir para o desenvolvimento de ações de promoção de saúde ${ }^{24}$.

Outra observação foi quanto ao horário de execução, visto que as atividades educativas eram executadas em período letivo, no horário de aula, o que fazia com que muitos alunos quisessem fugir de suas atividades letivas para participar das 
atividades junto aos discentes de graduação. Tais questões foram abordadas nas reuniões de avaliação e propostas de resolução de estratégias estão sendo desenvolvidas para serem aplicadas em momentos futuros.

Relatos prévios corroboram com as conclusões de presente estudo ${ }^{24}$, confirmando a eficácia da parceria com a escola na construção de hábitos de prevenção de doenças bucais na medida em que atua como agente transmissor de cuidados de higiene e informações sobre saúde bucal. Adicionalmente, a utilização de estratégias de ensino com atividades dinâmicas e divertidas estão entre as que mais motivam e estimulam os discentes de graduação ${ }^{26}$.

\section{CONCLUSÃO}

Com base nos resultados obtidos conclui-se que relacionar saúde e educação por meio de dinâmicas lúdicas educativas colaborou para que os objetivos esperados fossem atingidos, dado que atividades lúdicas despertaram o interesse e atraíram atenção e participação dos escolares.

\section{AGRADECIMENTOS}

Os autores agradecem o auxílio financeiro recebido do edital PROEXT/2014-2015/MEC/SESu vinculado ao projeto de extensão "Saúde na escola: educação, prevenção e diagnóstico de problemas da cavidade bucal, audição e fala de pré-escolares e professores", sob a coordenação da última autora; ao apoio logístico e de pessoal da Secretária Municipal de Saúde do Rio de Janeiro (SMS-RJ); aos escolares e professores da Escola Municipal CIEP Henfil; e a toda equipe executora (discentes de graduação, bolsistas e voluntários, discentes de pós-graduação, técnico-administrativos e docentes) do projeto de extensão.

\section{ABSTRACT \\ Application of educational dynamics on}

\section{health during School Health Week: experience report}

The university extension allows the university to approach society, and the resulting exchange of information can encourage the construction of technical and scientific knowledge. The aim of this article is to describe the experience of the development of general and oral health promotion actions, developed in an extension project of the School of Dentistry of the Federal University of Rio de Janeiro. Playful activities were selected as didactic means and applied to schoolchildren (aged 8 to 13) at Henfil Municipal School, CIEP HENFIL - RJ. Health topics were selected according to schoolchildrens' needs and involved dynamics of the senses and dynamics of self-care. The executing team was formed of professors, administrative technicians, and undergraduate students. Participants included 150 children who showed interest and curiosity in the activities. In addition, the participants formed bonds with undergraduate students, which facilitated collaborative relationships in which students felt safe to share their anxieties and insecurities regarding the issues addressed in the activities. The present work highlights the process of constructing ideas, designing activities, acquiring materials, executing the study, and the application of dynamics, experiences, and main results.

Descriptors: Community-Institutional Relations. Teaching. Health.

\section{REFERÊNCIAS}

1. Brasil. Plano nacional de extensão universitária. Brasília-DF, 2001. [Acesso em 01 nov. 2015]. Disponível em: http://porteiras.r.unipampa.edu.br/portais/fil es/2010/07/02_Politica_Nacional_Extensão .pdf.

2. Fórum de pró-reitores de extensão das instituições públicas de educação superior brasileiras (FORPROEX). Política Nacional de Extensão Universitária. Gráfica da UFRGS. Porto Alegre, RS, 2010 (Coleção Extensão Universitária; v. 7). [Acesso em 02 nov. 2019]. Disponível em: https:// www.ufrgs.br/prorext/wpcontent/uploads/2 
015/ 10/PNE_07.11.2012.pdf.

3. Nogueira MDP. Extensão Universitária: diretrizes conceituais e políticas: Documentos Públicas Brasileiras. Básicos do Fórum Nacional de Pró-Reitores de Extensão das Universidades Belo Horizonte: PROEX/UFMG; Fórum 2000. [Acesso em 02.nov. 2019]. Disponível em: https://www.ufmg.br/proex/renex/images/a valia\%C3\%A7\%C3\%A30_da_extens\%C3 \%A3o-_livro_8.pdf.

4. Brasil. Ministério da Educação. Conselho Nacional da Educação. Câmara da Educação Superior. Resolução CNE-CES n. 3. Instituiu as Diretrizes Curriculares Nacionais do Curso de Graduação em Odontologia. Brasília, 2002. [Acesso em 21 fev. 2020] Disponível em: http://portal.mec.gov.br/cne/arquivos/pdf/C ES032002.pdf4.

5. Brasil. Ministério da Educação. Conselho Nacional da Educação. Câmara da Educação Superior. Resolução CNE-CES n. 5. Instituiu as Diretrizes Curriculares Nacionais do Curso de Graduação em Fonoaudiologia. Brasília, 2002. [Acesso em 21 fev. 2020] Disponível em: http://portal.mec.gov.br/cne/arquivos/pdf/C ES052002.pdf.

6. Ministério da Educação - Conselho Nacional de Educação - Câmara de Educação superior. Resolução $n^{\circ} 7,18$ de dezembro de 2018. [Acesso em 12 nov. 2019]. Disponível em: http://portal.mec.gov.br/index.php?option= com docman\&view $=$ download \&alias $=104$ 251-rces007-18\&category_slug=dezembro2018-pdf\&Itemid=30192.

7. Resolução CEG número 02/2013 [Acesso em 11 fev. 2020]. Disponível em: https://xn-extenso-2wa.ufrj.br/images/Creditacao/CEG 2013 02.pdf.

8. Resolução CEG número 03/2014 [Acesso em 11 fev. 2020]. Disponível em: https://xn-extenso-2wa.ufrj.br/images/Creditacao/ CEG2014_03_disciplinas_mistas.pdf.

9. Lima SC, Magalhães MA, Santos FO. Território escolar, práticas e ações: promoção da saúde na escola. Revista Eletrônica de Geografia, 2012; 4(12): 144156. [Acesso em 20 fev. 2020]. Disponível em: http://www.observatorium.ig.ufu.br/ pdfs/4edicao/n12/08.pdf.

10. Miranda J, Lemos M, Torres M, Sovieiro V, Cruz R. Promoção de saúde bucal em odontologia: uma questão de conhecimento e motivação. Rev CROMG. 2000; 6(3):15457.

11. Gonçalves FD, Catrib AM, Vieira NF, Vieira LJ. A promoção da saúde na educação infantil. Interface - Comunic Saúde Educ. 2008;12(24):181-92.

12. Cavallieri F, Lopes GP. Índice de desenvolvimento social- IDS: comparando as realidades microurbanas da cidade do Rio de Janeiro. Coleção estudos cariocas. Abril 2008. [Acesso em 27 mar. 2020] Disponível em: http://portalgeo.rio.rj.gov.br/estudos cariocas/download/2394_\%C3\%8Dndice\% 20de\%20Desenvolvimento\%20Social_IDS. pdf.

13. Silva TAC, Gonçalves KGF. Manual de Lazer e Recreação: o mundo lúdico ao alcance de todos. São Paulo, SP: Phorte Editora, 2010.

14. Couto AS, Souza PH. Metodologias ativas como estratégia pedagógica para promoção do ensino-aprendizagem em Odontologia: relato de experiência. Rev ABENO. 2019; 19(2):91-100.

15. Franco LL, Martorell LB, Reis LB, Tavares GG. Estação sensorial temática: recurso pedagógico para formação do cirurgiãodentista na produção do cuidado em saúde. Rev ABENO. 2017;17(4):193-202.

16. Spricigo CB. Estudo de caso como abordagem de ensino. Pontifícia Universidade Católica do Paraná. Paraná-PR 2014. [Acesso em 08 nov. 2019]. Disponível em: https://www.pucpr.br/wp-content/upl oads/2017/10/estudo-de-caso-como-aborda gem-de-ensino.pdf.

17. Brasil. Fundação Nacional de Saúde. Diretrizes de educação em saúde visando à promoção da saúde: documento base Documento I. Brasília, DF: Funasa, 2007. 
[Acesso em 02 nov. 2019]. Disponível em: http://www.funasa.gov.br/site/wp-content/ files_mf/dir_ed_sau.pdf.

18. Brasil. Ministério da Saúde. Secretaria de Atenção à Saúde. Política Nacional de Humanização da Atenção e Gestão do SUS. O Humaniza SUS na atenção básica. Brasília, DF, 2009. [Acesso em 01 nov. 2019]. Disponível em: http://bvsms.saude. gov.br/bvs/publicacoes/humaniza_sus_aten cao_basica.pdf.

19. Aquilante AG, Almeida BS, Martins de Castro RF, Xavier CR, Sales Peres SH, Bastos JR. The importance of dental health education for preschool children. Rev Odontol UNESP. 2003;32(1):39-45.

20. Mitre RM, Gomes RA. Promoção do brincar no contexto da hospitalização infantil como ação de saúde. Ciênc Saúde Colet. 2004;9(1)147-54.

21. Frota MA, Gurgel AA, Pinheiro MC, Martins MC, Tavares TA. O lúdico como instrumento facilitador na humanização do cuidado de crianças hospitalizadas. Cogitare Enferm. 2007;12(1): 69-75.

22. Oliveira RR, Oliveira IC. Os doutores da alegria na unidade de internação pediátrica: experiências da equipe de enfermagem. Anna Nery Rev Enferm. 2008;12(2):230-6.

23. Bernardi MC, Massaroli A, Ribeiro KR, Gomes DC, Silveira SK, do Prado ML. Um diálogo sobre avaliação da aprendizagem: relato de experiência. Rev Iberoam Educ Invest Enferm. 2015;5(2):40-6.

24. Cardoso AT, Correia EP, Fernandes DE, Limírio JO, Rezende MC. Experiência de educação em saúde bucal em escola de educação infantil na República de Cabo Verde, África. Arch Health Invest. 2019; 8(5):267-70.

25. Cota AL, Costa BJ. Atividades lúdicas como estratégia para a promoção da saúde bucal infantil. Rev Saúde Pesq. 217; 10(2):365-71.

26. Santos CP, Costa CM, Bezerra IS, Assunção LR, Westphalen FH, Fernandes A. Estratégias criativas no processo ensinoaprendizagem da Radiologia Odontológica. Rev ABENO. 2016; 16(4):40-50.

\section{Correspondência para:}

Lucianne Cople Maia

e-mail: rorefa@terra.com.br

Departamento de Odontopediatria e Ortodontia

Faculdade de Odontologia da UFRJ

Rua Prof. Rodolpho Paulo Rocco, 325

Cidade Universitária

21941-617 Rio de Janeiro/RJ 